\title{
WHAT IS THE INTERNAL POINT OF VIEW?
}

\author{
Scott J. Shapiro* \\ INTRODUCTION
}

John Austin famously claimed that the idea of sanctions is "the key to the science[] of jurisprudence."1 Thus, he held legal rules to be threats backed by sanctions and statements of legal obligations as predictions that the threatened sanctions will be carried out. And before The Concept of Law was published in 1961, the concept of sanctions was central to every other positivistic theory of law as well. Although Hans Kelsen sought to explain legal rules and obligations in terms of norms, he understood these norms to be directives to courts requiring that sanctions be applied. Splitting the difference between Austin and Kelsen, Alf Ross conceived of legal rules as norms addressed to courts directing the use of sanctions and statements of legal validity as predictions that these norms will be followed.

In The Concept of Law, H.L.A. Hart showed that sanction-centered accounts of every stripe ignored an essential feature of law. This feature he termed "the internal point of view." Seen from the internal point of view, the law is not simply sanction-threatening, -directing, or -predicting, but rather obligation-imposing.

Though the internal point of view is perhaps Hart's greatest contribution to jurisprudential theory, this concept is also often and easily misunderstood. This is unfortunate, not only because these misreadings distort Hart's theory, but, more importantly, because they prevent us from appreciating the true infirmities of sanction-centered theories and the compelling reasons why they ought to be rejected.

In this essay, I try to address some of these confusions. What, exactly, is the internal point of view? What role (or roles) does it play in Hart's theory? And how does an adequate appreciation for the centrality of the internal point of view lead to the rejection of sanction-centered theories?

Briefly, my answers will be as follows. The internal point of view is the practical attitude of rule acceptance - it does not imply that people who accept the rules accept their moral legitimacy, only that they are disposed to guide and evaluate conduct in accordance with the rules.

\footnotetext{
* Professor of Law and Professor of Philosophy, University of Michigan, Ann Arbor. Thanks to Ben Zipursky for very helpful comments on a previous version of this draft.

1. John Austin, The Province of Jurisprudence Determined and the Uses of the Study of Jurisprudence 13 (1954).
} 
The internal point of view plays four roles in Hart's theory: (1) It specifies a particular type of motivation that someone may take towards the law; (2) it constitutes one of the main existence conditions for social and legal rules; (3) it accounts for the intelligibility of legal practice and discourse; (4) it provides the basis for a naturalistically acceptable semantics for legal statements.

Finally, sanction-centered theories are unacceptable for three reasons: (1) They are myopic in that they ignore or obscure one of the motivations that people might have for obeying the law; (2) they are unable to account for the existence of legal systems; (3) they cannot account for the intelligibility of legal practice and discourse.

\section{I. "INSIDER'S" VERSUS “INTERNALIZED"}

It is commonly thought that the "internal" point of view is synonymous with the "insider's" point of view. According to Stephen Perry, for example, "The general idea of the internal point of view is that an adequate jurisprudential account of law must at some point take into consideration how the practice looks to at least some of the practice's participants, from the inside." 2 Likewise, Gerry Postema writes, "The law, like other similar social practices, is constituted not only by intricate patterns of behavioral interaction, but also by the beliefs, attitudes, judgments, and understandings of participants. The practice has an 'inside,' the 'internal point of view' of participants."3

On this reading, Hart's doctrine of the internal point of view is a methodological prescription that demands that legal theories resonate with the shared experiences of legal natives. Jurisprudence must take the point of view (or views) of the insider: It must be "hermeneutic" in orientation. Legal theories that take into account the internal point of view are thus to be contrasted with ones that ignore the beliefs and attitudes of those who live under the law. The clearest examples of "external" theories are those motivated by concerns of philosophical behaviorism. Many sociological theories of law are external accounts in this sense insofar as they limit the observer's role to recording the frequency of compliance in a given population and correlating its absence with the appearance of sanctions. ${ }^{4}$

I do not think that this interpretation of the internal point of view can be correct, however. ${ }^{5}$ This is seen most plainly from Hart's use of the internal point of view to discredit sanction-centered theories of law, such as those

2. See Stephen R. Perry, Interpretation and Methodology in Legal Theory, in Law and Interpretation 97, 99 (Andrei Marmor ed., 1995).

3. Gerald J. Postema, Jurisprudence as Practical Philosophy, 4 Legal Theory 329, 332 (1998); see also Brian Leiter, Rethinking Legal Realism: Toward a Naturalized Jurisprudence, 76 Tex. L. Rev. 267, 295 n.126 (1997).

4. See, e.g., Donald Black, The Behavior of Law 6-8 (1976).

5. I discuss the matter in much greater detail in my reply to Stephen Perry. See Scott J. Shapiro, The Bad Man and the Internal Point of View, in The Path of the Law and Its Influence: The Legacy of Oliver Wendell Holmes, Jr. 197 (Steven J. Burton ed., 2000). 
proposed by Oliver Wendell Holmes and Hans Kelsen. Hart argued that these theories are myopic because they ignore or mask the range of attitudes that people typically have towards the law. The problem with "bad man" theories such as Holmes's is that they assume that people are motivated to follow the law solely to avoid sanctions, rather than because rules require such behavior. These theories, Hart says, "define [the internal point of view] out of existence." 6 The problem with Kelsen's theory, he claims, is that it focuses exclusively on one technique that the law uses to motivate conduct to the exclusion of all others. The law not only directs officials to punish those who do not comply with the rules, but it also provides guidance for those who want to live up to their obligations. ${ }^{7}$

If the internal point of view simply means the insider's point of view, then this critique would be unintelligible. After all, Holmes's bad man is an insider himself, namely, one whose curiosity about the law is aroused solely by his aversion to sanctions. Holmes's theory, therefore, does not define the insider's point of view out of existence; rather, his account is every bit as hermeneutic as Hart's. The problem with Holmes's theory, rather, is that it privileges one type of insider's point of view over another. By focusing solely on the perspective of the bad man, sanction-centered theories define the other point of view, namely, the internal point of view, out of existence.

What, then, is the internal point of view? As Hart used the term, the internal point of view refers to the practical attitude of rule acceptance. Someone takes this attitude towards a social rule when he accepts or endorses a convergent pattern of behavior as a standard of conduct. Thus, the internal point of view refers to a specific kind of normative attitude held by certain insiders, namely, those who accept the legitimacy of the rules. Hart is very clear on this point:

[F]or it is possible to be concerned with the rules, either merely as an observer who does not himself accept them, or as a member of the group which accepts and uses them as guides to conduct. We may call these respectively the 'external' and the 'internal points of view."

As this passage makes plain, the "internal" point of view is synonymous with the "internalized," rather than the "insider's," perspective. Whereas the phrase "the internal point of view" is univocal-it refers to a specific practical attitude - the "external point of view," on the other hand, is dangerously ambiguous. This is because there are at least two ways in which an attitude can be opposed to the internal point of view. Because the internal point of view is the practical attitude of norm-acceptance, a practical attitude towards the law that does not involve acceptance would qualify as an external attitude. The standpoint of Holmes's bad man is external in this sense. But an attitude might be external by failing to be a practical attitude at all. Someone whose interest in the law is primarily

6. H.L.A. Hart, The Concept of Law 91 (2d ed. 1994).

7. See id. at 40.

8. Id. at 89 . 
theoretical, who simply wishes to describe how members of a group regard and respond to a set of rules and, perhaps, who wishes to make predictions as well, takes the external point of view in this second sense.

Making matters more complicated, there are actually two different theoretical points of view one can take towards the law. First, one might seek to describe social behavior without recourse to the beliefs and attitudes of those whose lives are subject to the demands of legal institutions. In the absence of this information, the observer must be content with recording the frequency of compliance in a given population and correlating its absence with the appearance of sanctions. Hart calls this behaviorist stance the "extreme" external point of view. ${ }^{9}$ By contrast, one might seek to describe social behavior by attending to the attitudes of the members of the group. This "hermeneutic" point of view seeks to describe the law, in other words, by reference to the insider's point of view.

Hart himself, qua legal theorist, actually takes the external point of view towards the law, though here external means theoretical and the particular theoretical stance is hermeneutic. ${ }^{10}$ It is precisely because he takes a hermeneutical perspective towards the law that he rejects sanction-centered theories, for, although such theories take into account the bad man's point of view, they ignore the internalized point of view. Though hermeneutic, they are nevertheless myopic.

Figure 1 in this essay attempts to summarize this rather confusing set of distinctions and terminology. The most fundamental distinction that Hart draws is between the practical and theoretical points of view. The practical point of view is that of the insider who must decide how he or she will respond to the law. The theoretical perspective is that of the observer, who is often, but not necessarily, an outsider, who studies the social behavior of a group living under law.

With respect to the practical point of view, there are two attitudes that the insider can take towards the rules: acceptance and nonacceptance. Anyone who accepts the rules has, according to Hart, taken the internal point of view. Anyone who does not accept the rules, either because he is like the bad man and takes the practical, but non-accepting, point of view, or because he is merely observing and hence does not take a practical stance at all, has taken the external point of view.

Likewise, with respect to the theoretical point of view, there are two types of stances the observer can take. She can either take the hermeneutic point of view, which Hart himself takes, or she can take a behavioristic one. As mentioned, both the hermeneutic and behaviorist stances are external

9. Id.

10. H.L.A. Hart describes his methodological approach as "hermeneutic" in the introduction to his Essays in Jurisprudence and Philosophy. See H.L.A. Hart, Essays in Jurisprudence and Philosophy 13 (1983) ("[W]hat is needed is a 'hermeneutic' method which involves portraying rule-governed behaviour as it appears to its participants ....”). 
points of view in Hart's sense, although Hart describes the latter as the "extreme" external point of view.

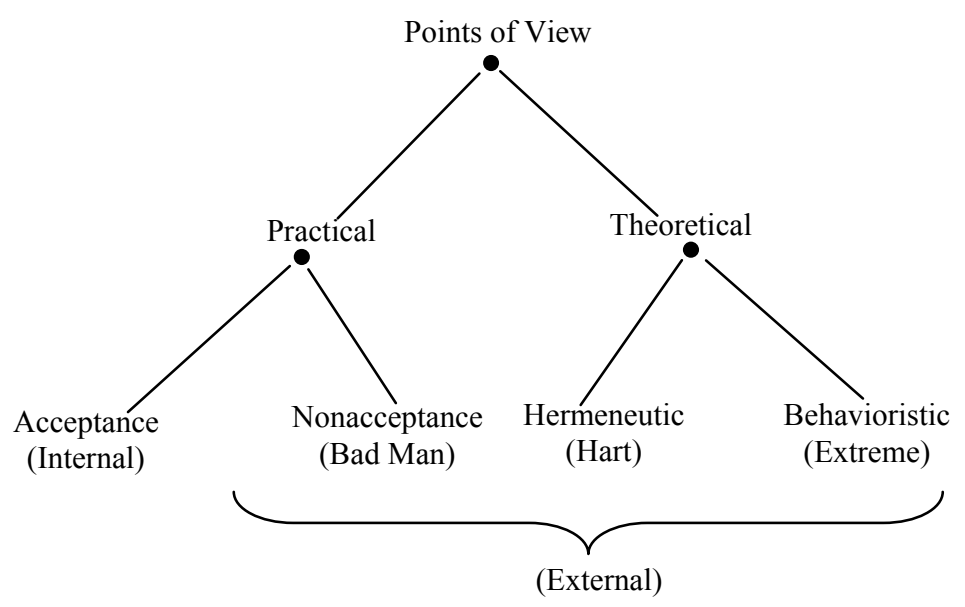

Figure 1

\section{TO ACCEPT A RULE}

Hart's internal point of view, therefore, is the practical attitude of rule acceptance. But what exactly does it mean to "accept" a social rule? Here things get a bit murky. Hart says that to accept a social rule is to regard a pattern of behavior "as a general standard to be followed by the group as a whole." 11 It is to treat existence of the rule as a "reason and justification"12 for action, as the "basis for claims, demands, admissions, criticism, or punishment,"13 and as establishing the "legitima[cy]"14 of these demands and criticisms. ${ }^{15}$

Given Hart's description, it is natural to think that to take the internal point of view is to believe that the rule is a legitimate standard of conduct, where legitimacy is understood as moral legitimacy or legitimacy from the perspective of right reason.

This interpretation would be mistaken, however. Hart is quite clear that one does not have to believe in the moral legitimacy of the law in order to accept its authority:

11. Hart, supra note 6 , at 56 .

12. Id. at 11 (emphasis omitted).

13. Id. at 90 .

14. Id. at 56 .

15. Hart notes that to take the internal point of view is not to experience particular "feelings of compulsion." Id. at 57, 88. Rather, it is to possess a "critical reflective attitude." See id. at 57. 
But the dichotomy of 'law based merely on power' and 'law which is accepted as morally binding' is not exhaustive. Not only may vast numbers be coerced by laws which they do not regard as morally binding, but it is not even true that those who do accept the system voluntarily, must conceive of themselves as morally bound to do so, though the system will be most stable when they do so. In fact, their allegiance to the system may be based on many different considerations: calculations of long-term self-interest; disinterested interest in others; an unreflecting inherited or traditional attitude; or the mere wish to do as others do. ${ }^{16}$

From Hart's perspective, people can have any number of reasons for accepting rules. They may be guided by a rule because they think that it is in their long-term self-interest to be so committed. Judges might apply the law simply to pick up their paychecks.

Given that the internal point of view is not necessarily the moral point of view, what does Hart mean when he characterizes it as acceptance of a rule as a standard of conduct? The best way to understand Hart's position is to examine the various ways in which he thought the internal point of view is expressed. ${ }^{17}$

The attitude manifests itself most obviously through conforming behavior. When one takes the internal point of view towards a rule, one acts according to the dictates of the rule. ${ }^{18}$ Of course, there must be something more to the internal point of view, given that the bad man also conforms to the rules. The second way in which the internal point of view is expressed is through critical evaluation. ${ }^{19}$ Thus, participants who accept the rules criticize others, and perhaps even themselves, for failing to conform to the rules. Furthermore, not only do deviations from the rule engender criticism, but such criticism is deemed to be legitimate and made with good reason. ${ }^{20}$ Presumably, the acknowledgment of the criticism's legitimacy is signaled, at least in part, by the fact that the criticizers are not themselves criticized for engaging in the criticism.

Finally, the internal point of view is usually expressed by statements that use normative terminology such as "ought," "must," "right," and "wrong." 21 Thus, if someone accepts the rule that men must bare their heads upon entering a church, this practical attitude might be expressed by statements of the form, "You ought to take off your hat in Church" or "It was wrong of me not to take off my hat last Sunday." Hart calls these statements "internal statement[s]," because they normally express the internal point of view. ${ }^{22}$ Hart contrasts these practical statements with

16. Id. at 203 (emphasis added).

17. Id. at 56-57, 88-91. For an excellent discussion of Hart's practice theory of rules, see Joseph Raz, Practical Reason and Norms 49-58 (2d ed. 1990).

18. Hart, supra note 6, at 55-56.

19. Id. at 55 .

20. Id. at 55-56.

21. Id. at 57.

22. Id. at 102-03 (emphasis omitted). 
theoretical statements that others accept a particular rule. For example, someone might say, "Episcopalians accept a rule requiring men to take off their hats in Church." Hart calls these "external statements" because they usually express the external point of view. ${ }^{23}$ They are statements that a particular group accepts certain rules normally made by those who do not accept those rules themselves.

We should understand Hart's internal point of view as a commitment to act in all of the above ways. That is, one takes the internal point of view towards a rule when one intends to conform to the rule, criticizes others for failing to conform, does not criticize others for criticizing, and expresses one's criticism using evaluative language. This interpretation is confirmed by Hart's postscript: "[Acceptance] consists in the standing disposition of individuals to take such patterns of conduct both as guides to their own future conduct and as standards of criticism which may legitimate demands and various forms of pressure...."24 This "standing disposition," furthermore, can be instilled or adopted for any reason whatsoever.

[S]ome rules may be accepted simply out of deference to tradition or the wish to identify with others or in the belief that society knows best what is to the advantage of individuals. These attitudes may coexist with a more or less vivid realization that the rules are morally objectionable. ${ }^{25}$

\section{THE EXISTENCE CONDITIONS FOR SOCIAL RULES}

In the previous section, I described the internal point of view as the practical attitude of rule acceptance and showed one negative use that this concept plays within Hart's theory. As we saw, the existence of the internal point of view is used to discredit the positivistic accounts of Hart's predecessors, namely, the sanction-centered theories of Austin, Kelsen, Ross, and Holmes. The flip side of this critique, of course, is the positive explanatory role that rule acceptance plays in Hart's account, namely, that the reason why some members of groups act as they do is because they accept certain rules from the internal point of view. This point of view explains why they conform to their rules, criticize deviations, and couch their guidance and evaluations in normative terminology.

We might say that Hart's rejection of sanction-centered theories stems, at least in part, from his desire to develop a general theory of law. Hart insisted that a jurisprudential theory take into account and study all of the methods that the law provides for the guidance of conduct. As Hart rhetorically asks, why should the law (and hence legal theory) not also care about the "'puzzled man' or 'ignorant man' who is willing to do what is required, if only he can be told what it is?" 26 An adequate jurisprudential

23. Id. at 103 (emphasis omitted).

24. Id. at 255 .

25. Id. at 257 .

26. Id. at 40 . 
theory must include within its ambit the fact that the law may guide conduct either through its rules or through the sanctions attached to its rules. ${ }^{27}$

To be sure, Hart did privilege the internal point of view in his theory of the law. While he thought that everyone in a given group might take the internal point of view, he claimed that it is impossible for everyone to take the external point of view. At the very least, legal officials would have to be committed to the law if we were to say that a group had a legal system. In this section, I would like to explain Hart's reasons for taking this position.

Recall that according to Austin, a rule is a legal rule just in case it was issued, explicitly or tacitly, by someone who is habitually obeyed and does not habitually obey anyone else. Habits, therefore, are central to Austin's conception of sovereignty and legality. Hart argued, however, that habits cannot underpin sovereignty because habits cannot confer rights and authority. For this, social rules are needed.

Hart develops his theory of social rules via a comparison with social habits. ${ }^{28}$ Social rules and habits are similar, according to Hart, in one important respect: Both are behavioral regularities. ${ }^{29}$ Although it is not necessary that every member of the group engage in the behavior, most must for a social rule or habit to exist. ${ }^{30}$

Apart from this commonality, there are three salient differences between social rules and habits. First, deviations from social rules, as opposed to habits, engender criticism by members of the group. ${ }^{31}$ Second, these criticisms are taken to be legitimate. ${ }^{32}$ Third, when a social habit exists, those who engage in the pattern of behavior need not be aware that they are engaged in the behavior, nor need they intend to teach others to engage in it or seek to maintain it. ${ }^{33}$ By contrast, a group has a social rule only when members of the group treat the existing pattern of behavior as a common standard for behavior. The group has a social rule, in other words, when they take the internal point of view towards a certain behavioral regularity. ${ }^{34}$

Social rules, therefore, have what Hart calls both an external and internal aspect. ${ }^{35}$ They have an external aspect, which they share with habits, in that most members of the group conform to the behavior. Social rules and habits are regularities of behavior. But they also have an internal aspect, in that these regularities are explained by the fact that members of the group

27. See id. at 91 .

28. Id. at 55-60.

29. See id. at 55.

30. Id.

31. Id.

32. Id. at 55-56.

33. Id. at 56 .

34. Id. at 56-57.

35. Id.; see also id. at 88-91. 
possess a critical reflective attitude. Members of the group act as a rule because they accept that there is a rule.

It is crucial to note that Hart is not simply setting out conditions under which it is proper to say that a group accepts a social rule or that the group has a rule. He is proposing conditions for the existence of social rules. ${ }^{36}$ According to Hart, a social rule exists in a group $G$ just in case members of the group engage in a certain practice from the internal point of view. On Hart's account, therefore, the sovereign has the right to create rules if, and only if, there exists a social practice of treating his directives as binding. This practice cannot be a mere habit but must have an internal aspect as well. Members of the group cannot simply act in accordance with the sovereign's will, but must act because of it.

Thus far, we have been discussing Hart's theory of social rules, in which social rules exist only when they are practiced. Hart also recognizes that rules might exist even though they are not followed. Jaywalking may be illegal, for example, even though everyone does it. The rule prohibiting jaywalking, in other words, exists in some jurisdictions even though there is little conforming behavior.

For Hart, a rule $\mathrm{R}_{1}$ may be said to exist even in the absence of a social practice when there exists some other social rule $R_{2}$ that requires certain members of the group to heed $\mathrm{R}_{1}$. In Hartian terminology, a primary rule exists when it is "validated" by a secondary rule. ${ }^{37}$ We might say, for example, that the jaywalking rule exists or is legally valid because it is validated by the rule of recognition in the jurisdiction in question. The warrant for such statements depends on the fact that legal officials take the internal point of view towards their rule of recognition.

The existence of the internal point of view, therefore, underwrites the existence of all legal rules. Without supposing that officials take the attitude of norm-acceptance to the rule of recognition, there could be no rule of recognition and hence law could not exist as a conceptual matter. To the extent that sanction-centered theories fail to countenance the existence of such attitudes, they fail to account for the very possibility of legal systems.

\section{The INTELLIGIBILITY OF LEGAL PRACTICE}

It is sometimes thought that Hart introduced the internal point of view in order to explain how social rules, and in turn the law, can give group members reasons for action. On this account, Hart criticized Austin for thinking that habits and threats can confer genuine rights and impose genuine obligations, where "genuine" here means from the perspective of

36. See, e.g., id. at 58 ("The acceptance, and so the existence, of such a rule will be manifested during Rex I's lifetime in part by obedience to him, but also by acknowledgements that obedience is something to which he has a right by virtue of his qualification under the general rule." (emphasis added)); see also id. at 109-10.

37. See id. at 107-10. 
right reason. In contrast to habits and threats, he argued, only social rules are reason-giving entities. Social rules have this normative power because they are regularities of behavior accepted from the internal point of view.

Given this interpretation, of course, Hart's claims are thoroughly perplexing, for he never explains how the internal point of view imbues rules with normative force. After all, social rules differ from habits in that the former are constituted by two types of social regularities, namely, behavioral and attitudinal, whereas habits are constituted merely by one type of social regularity. Hart, though, does not tell us why this second regularity makes a difference. How does the fact that legal officials think that the sovereign has the right to rule actually give him the right to rule? And how does the fact that most members of the group believe that others have a reason or an obligation to $\Phi$ give them a reason or obligation to $\Phi$ ? As Jules Coleman and Brian Leiter have put it,

The claim that the authority of a social rule derives from the internal point of view thus amounts to the view that what makes a norm reason giving is the fact that the majority of individuals treat it as such. But the authority of a rule (its reason-giving capacity) cannot be grounded in the mere fact that individuals treat it as reason giving. ${ }^{38}$

Clearly, Hart did not intend for the internal point of view to provide an explanation for the reason-giving nature of social rules and law. Indeed, I do not believe that Hart thought it the task of legal theory to provide any such explanation. I argue instead that Hart's aim in introducing the internal point of view was, in addition to the two previously mentioned, to render the thoughts and discourse of legal actors comprehensible. ${ }^{39}$ The internal point of view, in other words, does not explain the morality or rationality of legal activity, but rather its very intelligibility.

One way to appreciate Hart's critique of Austin is to imagine how actors who lived in an Austinian system would conceive of their habitual obedience. Is it possible for anyone to understand his or her deference to the sovereign as recognizing the sovereign's right to rule? Clearly not. Habits, Hart reminds us, are not normative activities. ${ }^{40}$ Someone who engages in a habit does not take the habit as a standard of conduct and attempt to conform to it. Indeed, one may not even be aware that he has the habit. Furthermore, one does not criticize oneself for failing to act in a habitual manner. Except in bizarre circumstances, no one says to oneself,

38. Jules L. Coleman \& Brian Leiter, Legal Positivism, in A Companion to Philosophy of Law and Legal Theory 241, 247 (Dennis Patterson ed., 1996). Jules Coleman and Brian Leiter go on to offer an argument for the reason-giving nature of the internal point of view. Regardless of whether these arguments are successful, I don't think that they represent an accurate interpretation of Hart's theory (and, judging by Coleman's later work, see Jules L. Coleman, The Practice of Principle: In Defence of a Pragmatist Approach to Legal Theory 103 (1998), neither does Coleman). do.

39. "Legal actor" refers to anyone who intends to do what the law requires him or her to

40. See Hart, supra note 6, at 56. 
"I should have said 'um' more often today." By contrast, those who accept rules that require deference to the sovereign do recognize the sovereign's right to rule. They regard themselves as being bound by his pronouncements and justified in criticizing others for failing to obey. For them, the sovereign is the sovereign.

The same exercise shows the inadequacies of Austin's theory of obligation. Is it intelligible for anyone to regard the threats of the sovereign as creating obligations? Again, the answer is clearly no. Since one does not look upon the sovereign as having the right to rule, one does not regard his words as creating standards of conduct. If one believed it possible to escape punishment, then he would regard himself free to disobey. Nor would he criticize anyone else for disobeying. However, those who respond to the directives of the sovereign not simply as threats, but as rules, do conceive of themselves and others as obligated to act accordingly. They accept the words of the sovereign as setting new standards of conduct and evaluation, as guiding them not just with accurate warnings of evil, but with legitimate demands of conduct.

Hart's aim in introducing the internal point of view, therefore, was not to account for the reason-giving nature of legal practice, but rather to explain the intelligibility of the activity. Insofar as participants conceive of the law as a social institution consisting of rights and obligations, they must, on the pain of incoherence, also accept certain rules that require and permit various courses of conduct. A theory like Austin's that does not admit rules, or their acceptance, thus renders incomprehensible the way legal participants think about their actions. Note that this critique of Austin is far more damaging than the one we first encountered in Part II. The claim here is not simply that Austin is wrong about the actual motivations of legal participants, but that he could not possibly be right. Because legal activity is rule-guided activity, a theory that privileged habits and sanctions over rules not only gives a poor explanation of the actions of participants, but, more importantly, fails to account for the coherence of their thoughts. ${ }^{41}$ As Hart pointed out,

The difference may seem slight between the analysis of a statement of obligation as a prediction, or assessment of the chances, of hostile reaction to deviation, and our own contention that ... its characteristic use is not to predict this but to say that a person's case falls under such a rule... Indeed, until its importance is grasped, we cannot properly understand the whole distinctive style of human thought, speech, and action which is involved in the existence of rules and which constitutes the normative structure of society. ${ }^{42}$

41. Note that Hans Kelsen's theory escapes this general criticism insofar as it treats the law as consisting of norms. See generally Joseph Raz, Kelsen's Theory of the Basic Norm, in The Authority of Law: Essays on Law and Morality 122-45 (1979).

42. Hart, supra note 6 , at 88 . 


\section{The SEMANTiCs of Legal Discourse}

There is one further role that the internal point of view plays in Hart's theory: It enables him to give naturalistically acceptable semantics for legal statements.

Although no longer popular as a philosophical position, at the time that Hart wrote The Concept of Law Scandinavian realism was in full bloom. The Scandinavian realists, such as Axel Hägerström, Karl Olivecrona, and Alf Ross, were skeptical of "rule-talk" and believed that thinking and speaking of rules as "existing" or as "legally valid" was tantamount to engaging in mysticism. ${ }^{43}$ Their skepticism stemmed from a commitment to an austere version of naturalism according to which normative facts do not exist. They sought, therefore, to render legal language empirically respectable by proposing predictive theories of legal obligation and validity. To say that a rule is legally valid, for these realists, is not to ascribe a "mysterious property" to a rule, but rather to make a prediction about the behavior of a court. In this way, legal statements would express naturalistically acceptable propositions.

As we have seen, Hart thought the predictive analysis to be a complete mistake, but he did sympathize with the Scandinavian impulse to make room for law in the natural world. Hart, therefore, proposed an account of legal semantics that attempted to make legal language naturalistically reputable. Again, the internal point of view plays the main role here.

Corresponding to the distinction between the internal and external points of view, Hart distinguishes between internal and external statements. ${ }^{44}$ An internal statement expresses the acceptance of a rule. In legal contexts, examples include statements of the form, "It is the law that ..." or "[t]he rule that... is legally valid." 45 According to Hart, such statements normally express two distinct attitudes. First, they express acceptance of the rule of recognition of the particular jurisdiction as the appropriate test for determining membership in the legal system. Second, internal legal statements express judgments that certain rules pass that test. Hart takes pains to note that such statements do not state those latter judgments. To say that it is the law that no vehicles are permitted in the park is not to say that the no-vehicles-in-the-park rule passes the tests of legal validity set out in the system's rule of recognition. Rather, the statement expresses that very judgment without stating it. ${ }^{46}$

43. See, e.g., Axel Hägerström, Inquiries Into the Nature of Law and Morals (Karl Olivecrona ed., C.D. Broad trans., 1953); Karl Olivecrona, Law as Fact (2d ed. 1971); Alf Ross, On Law and Justice (1958). For a general overview of Scandinavian Legal Realism, see Jes Bjarup, The Philosophy of Scandinavian Legal Realism, 18 Ratio Juris 1 (2005). For Hart's critique of this jurisprudential school, see Hart, Scandinavian Realism, in Hart, supra note 10 , at 161 .

44. Hart, supra note 6 , at 102-03.

45. Id.

46. See id. at 103 . 
On the other hand, external statements do not express the acceptance of a rule or its application. Statements such as, "In England, they recognize whatever the Queen in Parliament enacts," state the existence of a social rule. ${ }^{47}$ Of course, one who makes such a statement might in fact accept such a rule, but the statement itself does not express the acceptance.

External statements, therefore, are fact-stating, whereas internal statements are not. If I say, "They have a rule around here about men taking off their hats in church," I am making a statement about the world, namely, that a behavioral and attitudinal regularity exists within a certain group. If my statement is true, then the term "rule" actually refers to some hard social fact. By contrast, internal statements do not state facts. An internal legal statement is like the umpire's "out," expressing, though not stating, certain legal judgments. ${ }^{48}$

By claiming that all legal statements are either internal or external statements, Hart sought to secure the empirical respectability of legal language. To say, for example, that a rule is legally valid is not to state that some ghostly entity possesses some mystical property of validity. Rather, it is to express the attitudes of the speaker towards the rule of recognition and its applicability. Furthermore, to say that the rule of recognition exists does state a fact, but the rule referred to is anything but ghostly. It is simply a fact that certain people act and think a certain way.

Although he does not use such labels, Hart's semantic program might be described as being a mixture of cognitivism and non-cognitivism. With respect to understanding assertions about the existence of secondary legal rules, such as the rule of recognition, Hart is a cognitivist. These statements state propositions and, hence, are capable of being true or false. This cognitivism rests on a reductive account of social rules. For Hart, a social rule just is a social practice and, hence, to say that the rule of recognition exists is simply to state that a certain regularity of behavior is generally accepted as a standard of conduct. ${ }^{49}$ With respect to statements about the existence of primary legal rules, on the other hand, Hart is a non-cognitivist. These statements do not state propositions and, hence, cannot be true or false. This particular brand of non-cognitivism is a form of normexpressivism. ${ }^{50}$ To state that a legal rule is valid is to express the acceptance of a norm that requires that certain actions be followed.

Although Hart believed that the internal point of view enabled the legal theorist to give no-nonsense, naturalistically acceptable semantics for legal statements, Hart does not argue, nor is there reason to believe, that this is the only way to find a place for legal facts in the natural world. It is true that norm-expressivism is a very promising and appealing route for a

47. See id. at 102.

48. See id. at 102-03.

49. See id. at 110.

50. For a similar interpretation of Hart as an early norm-expressivist, see Kevin Toh, Hart's Expressivism and His Benthamite Project, 11 Legal Theory 75 (2005). 
naturalist to take, but it would be premature at this stage in the metaethical debate to suppose that no other semantic project could succeed.

It should also be pointed out that one does not have to go as far as Hart does in claiming that the very meaning of internal legal statements is given by their expressive function in order to see why sanction-centered theories such as Austin's, Holmes's, and Ross's, cannot be correct. ${ }^{51}$ With any plausible jurisprudential theory, legal statements will characteristically play an expressive role. When a judge says that one is obligated to pay one's taxes and that the failure to do so constitutes an offense, it seems as though the judge is expressing approval towards paying one's taxes and condemning the failure to do so. This is even more obvious when certain acts are considered wrong and the perpetrators are deemed guilty in a court of law.

But if a theory of law did not admit of rules, or their acceptance, one could not account for the expressive function of legal discourse. For, if we take all obedience to be mere habitual behavior, we will be overlooking the very attitudes typically expressed by statements such as "The sovereign has the right to be obeyed." Similarly, if someone is threatened with some harm unless he $\Phi$ 's, but we ignore his attitude towards the propriety of the threat or treat his statements about such threats as mere predictions about the likelihood of their execution, we will be unable to account for the pragmatic function of statements such as "I am obligated to $\Phi$."

\section{CONCLUSION}

Sanction-centered theories must be rejected for three reasons. First, they are myopic in that they focus exclusively on one type of motivation that people might have for obeying the law, namely, to avoid being sanctioned, while ignoring or effacing other reasons that they might have for compliance, namely, a concern for following the rules themselves. Second, they are incapable of explaining the very possibility of a legal system, for they overlook the attitudes of rule acceptance that are metaphysically responsible for the existence of law. Third, most such theories are incapable of accounting for the intelligibility of legal practice and discourse, for it is nonsensical to think or say that the law imposes certain obligations and confers certain rights unless one also accepted the rules that imposed those obligations and conferred those rights.

In each case, sanction-centered theories are flawed because they ignore the internal point of view. If a jurisprudential theory is to be general and account for the existence of law and the intelligibility of legal thought and discourse, then it must countenance the practical attitude of rule acceptance. So Hart argued, and in this regard I think he was right.

51. Kelsen's theory escapes this objection as well. See supra note 41. 